\title{
openheart Clinical prediction of incident heart failure risk: a systematic review and meta-analysis
}

\author{
Hong Yang, Kazuaki Negishi, Petr Otahal, Thomas H Marwick
}

To cite: Yang H, Negishi K, Otahal P, et al. Clinical prediction of incident heart failure risk: a systematic review and meta-analysis. Open Heart 2015;2:e000222. doi:10.1136/openhrt-2014000222

\section{- Additional material is available. To view please visit the journal (http://dx.doi.org/ 10.1136/openhrt-2014- 000222)}

Received 17 November 2014 Revised 15 February 2015 Accepted 17 March 2015

\section{CrossMark}

Menzies Institute for Medical Research, Hobart, Tasmania, Australia

\section{Correspondence to} Professor Thomas $\mathrm{H}$ Marwick;

Tom.Marwick@utas.edu.au

\section{ABSTRACT}

Background: Early treatment may alter progression to overt heart failure (HF) in asymptomatic individuals with stage B HF (SBHF). However, the identification of patients with SBHF is difficult. This systematic review sought to examine the strength of association of clinical factors with incident $\mathrm{HF}$, with the intention of facilitating selection for HF screening.

Methods: Electronic databases were systematically searched for studies reporting risk factors for incident HF. Effect sizes, typically HRs, of each risk variable were extracted. Pooled crude and adjusted HRs with 95\% Cls were computed for each risk variable using a random-effects model weighted by inverse variance.

Results: Twenty-seven clinical factors were identified to be associated with risk of incident $\mathrm{HF}$ in 15 observational studies in unselected community populations which followed 456850 participants over 4-29 years. The strongest independent associations for incident $\mathrm{HF}$ were coronary artery disease (HR=2.94; $95 \% \mathrm{Cl} 1.36$ to 6.33 ), diabetes mellitus (HR=2.00; $95 \% \mathrm{Cl} 1.68$ to 2.38), age (HR (per 10 years) $=1.80 ; 95 \% \mathrm{Cl} 1.13$ to 2.87 ) followed by hypertension ( $\mathrm{HR}=1.61 ; 95 \% \mathrm{Cl} 1.33$ to 1.96$)$, smoking ( $\mathrm{HR}=1.60 ; 95 \% \mathrm{Cl} 1.45$ to 1.77), male gender $(\mathrm{HR}=1.52 ; 95 \% \mathrm{Cl} 1.24$ to 1.87$)$ and body mass index (HR (per $\left.5 \mathrm{~kg} / \mathrm{m}^{2}\right)=1.15 ; 95 \% \mathrm{Cl} 1.06$ to 1.25 ). Atrial fibrillation (HR=1.88; $95 \% \mathrm{Cl} 1.60$ to 2.21), left ventricular hypertrophy $(\mathrm{HR}=2.46 ; 95 \% \mathrm{Cl} 1.71$ to 3.53) and valvular heart disease (HR=1.74; $95 \% \mathrm{Cl}$ 1.07 to 2.84 ) were also strongly associated with incident $\mathrm{HF}$ but were not examined in sufficient papers to provide pooled hazard estimates.

Conclusions: Prediction of incident HF can be calculated from seven common clinical variables. The risk associated with these may guide strategies for the identification of high-risk people who may benefit from further evaluation and intervention.

The incidence and prevalence of heart failure (HF) are growing and assuming epidemic proportions, affecting an estimated 23 million people worldwide. ${ }^{1}$ In the USA, 5 million people suffer from HF with a rate of 550000 new cases diagnosed each year. ${ }^{2}$ HF is predominantly a problem of old age, the most frequent cause of hospitalisation in the

\section{KEY MESSAGES}

What is already known about this subject?

- A variety of risk factors are known to be associated with heart failure (HF) - ranging from social determinants of health to lifestyle characteristics (smoking, physical inactivity, increased salt intake) and common comorbidities (hypertension (HTN), type 2 diabetes mellitus, coronary artery disease (CAD), obesity and metabolic syndrome and precursors of myocardial disease including a history of chemotherapy or a family history of cardiomyopathy.

What does this study add?

- The relative magnitude of these risk factors, and their combined effects, are not well known. This systematic review sought to examine the strength of association of clinical factors with incident $\mathrm{HF}$, with the intention of creating a practical clinical score to facilitate selection for HF screening. The strongest associations for incident $\mathrm{HF}$ (adjusted $\mathrm{HR} \geq 2$ ) were CAD ( $\mathrm{HR}=2.94$; $95 \% \mathrm{Cl} 1.36$ to 6.33 ) and diabetes mellitus ( $\mathrm{HR}=2.00 ; 95 \% \mathrm{Cl} 1.68$ to 2.38). Adjusted HRs $\geq 1$ were age (HR (per 10 years) $=1.80 ; 95 \% \mathrm{Cl}$ 1.13 to 2.87 ), HTN (HR=1.61; $95 \% \mathrm{Cl} 1.33$ to 1.96), smoking (HR=1.60; $95 \% \mathrm{Cl} 1.45$ to 1.77), male gender (HR=1.52; $95 \% \mathrm{Cl} 1.27$ to 1.59) and body mass index (HR (per $5 \mathrm{~kg} / \mathrm{m}^{2}$ ) $=1.15 ; 95 \%$ Cl 1.06 to 1.25 ).

How might this impact on clinical practice?

- The early detection of asymptomatic patients with left ventricular dysfunction is now possible with a variety of sensitive biochemical and imaging techniques, and should lead to the use of cardioprotective strategies to prevent progression of disease. The estimation of HF risk is a critical step in appropriate selection of patients for imaging.

elderly and a major burden on the community due to the cost of care and poor quality of life. The total direct and indirect cost of $\mathrm{HF}$ in the USA exceeds $\$ 30$ billion, ${ }^{3}$ where it accounts for 12-15 million office visits and 6.5 million hospital days each year. ${ }^{2}$ 
The morbidity and cost of late-stage $\mathrm{HF}$ may be delayed or even prevented by pharmacological interventions, once evidence of structural heart disease (stage B HF, SBHF) has been defined. ${ }^{4-9}$ Subclinical cardiac impairment is most readily identifiable in patients with prior myocardial infarction. Identification of SBHF in approximately $50 \%$ of patients with HF who are nonischaemic might be possible with echocardiographic or biochemical screening, ${ }^{10}$ but this would be most feasible if there was a means of identifying risk on clinical grounds. Various risk factors have been associated with $\mathrm{HF}$, ranging from lifestyle characteristics such as smoking, physical inactivity, increased salt intake and lower socioeconomic status to common comorbidities including hypertension (HTN), type 2 diabetes mellitus (T2DM), coronary artery disease (CAD), obesity and metabolic syndrome (MS). Risk factors also include a history of chemotherapy or a family history of cardiomyopathy. ${ }^{11}{ }^{12}$ We undertook a systematic review and meta-analysis of studies reporting risk factors relating to incident $\mathrm{HF}$ in unselected community-based populations. The goal of this was to identify a series of clinical markers which could be used to identify participants from a community-based population in whom further evaluation and intervention might be warranted.

\section{METHODS}

\section{Search strategy}

The research strategy, study selection and analysis method used in the study followed the Preferred Reporting Items for Systematic Reviews and Meta-Analyses statement (PRISMA) ${ }^{13}$ Electronic databases (MEDLINE, EMBASE) were systematically searched for published studies reporting risk factors related to incident HF. Search key terms were: 'incident heart failure' and 'risk factors', 'risk assessment', 'risk impact', 'risk prediction', 'risk score', 'risk prevention'. To ensure the identification of all relevant articles and publications, the reference lists of these articles were also reviewed to identify additional studies. The last search was performed on 7 October 2013.

\section{Study inclusion}

From these lists, studies were included if they met each of the following criteria: (1) studies of a full-length publication in a peer-reviewed English language journal; (2) studies carried out on human adults $>18$ years of age; (3) studies carried out on an unselected community population; (4) studies reporting risk factors relating to incident HF; (5) studies using Cox proportional hazard models reporting risk effect sizes in HR with $95 \%$ CIs and/or associated $\mathrm{p}$ value. This review incorporated mainly observational cohort studies.

\section{Outcomes}

The primary outcome of interest was incident HF. The criteria for identification of incident HF were described as one or more of the following: (1) medical diagnosis from physician's records; (2) evidence of treatment for HF (ie, diuretics and either digitalis or a vasodilator); (3) hospital or nursing home stays in which the participant had a discharge diagnosis with a code of International Statistical Classification of Diseases and related health problems (ICD-9 code of 428.0 to 428.9); (4) death certificate report in which the underlying cause of death was recorded using an ICD-9 code of 428.0 to 428.9 .

\section{Data extraction}

Data were extracted independently by reviewers (HY, KN and $\mathrm{PO}$ ). All discrepancies were reviewed and resolved by consensus. For the systematic review, the following data concerning the individual study populations were extracted: demographic and clinical characteristics and associated risk prevalence at baseline; study design; years of follow-up; statistical models; statistic models; risk effect sizes and their associated 95\% CIs with $\mathrm{p}$ values; covariates included in the risk assessment models in relation to outcome. In situations in which multiple articles were published from a single cohort, data were included only if different risk variables were analysed and reported.

\section{Statistical analysis}

Reported risk effect sizes and the statistical models used in each study were reviewed. Crude measures of effect with 95\% CIs were extracted for each risk variable. Multiple within-study effects stratified in subgroups were combined by weighting each group by its number of participants. Study risk estimates reported per categorical change were recalculated as continuous variables for body mass index (BMI) ${ }^{14}$ Risk estimates from the majority of studies were estimated using Cox proportional hazard models and pooled as HRs (although some incorrectly labelled these as relative risk/rate). ${ }^{15}{ }^{16}$ Risk estimates reported as 'Relative Risk' using the Mantel-Haenszel $^{17}$ or linear regression model ${ }^{18}$ or OR using the logistic regression mode ${ }^{19}$ were excluded for further analysis. Consequently, pooled risk estimates were all from studies using Cox proportional hazard models and were suitable for providing summary risk estimates. Both unadjusted and maximally adjusted risk effects were pooled using random-effects models weighted by inverse variance. ${ }^{20}$ Further, a subset of studies reporting seven mutually adjusted risk effects (age, male gender, BMI, smoking, HTN, diabetes mellitus (DM) and $\mathrm{CAD}$ ) were also pooled. When CIs were not reported, their associated $p$ values were used to estimate variance of the risk estimate. ${ }^{21}$

The Cochrane $Q$ statistic and $\mathrm{I}^{2}$ values index were used to assess the degree of heterogeneity across studies. Funnel plots were constructed and Egger's test was used to assess potential publication bias. Duval and Tweedie's trim and fill method was used to assess the potential effects of publication bias on risk estimates. Meta- 
regression was also performed for each risk factor to examine possible study factors associated with heterogeneity. The assessment of study quality was performed using the Newcastle-Ottawa Scale (NOS) for nonrandomised studies in meta-analyses. ${ }^{22}$ Statistical analysis was performed using statistics package R V.3.1.1.

\section{RESULTS}

\section{Study selection}

The process of article selection based on PRISMA guidelines is presented in figure 1. After exclusion of duplicates, the initial search revealed a total of 1974 original articles published from 1967 to 2013. After exclusion of inappropriate papers, or studies without relevant risk analysis, there were 15 studies eligible for inclusion, from which 4 had more than one eligible article either from the same data set or from a pilot study set. Therefore, a total of 20 articles were systematically reviewed and eligible for quantitative synthesis (figure 1). ${ }^{15-17} \quad 21 \quad 23-38$ Risk estimates from two articles $^{2324}$ were not included in the meta-analysis since they duplicated estimates from the same cohort, and estimates from Gottdiener $e t a l^{16}$ and Mujib et $a l^{21}$ were only included where they were absent from the corresponding articles on the same cohorts; a similar approach was applied to risk estimates from Butler $e t a l^{26}$ and Kalogeroupoulos et al, ${ }^{17}$ respectively. The included articles were published between 1993 and 2013.

\section{Baseline characteristics}

The baseline demographic characteristics of included studies (15 prospective cohort studies) are summarised in table 1. The geographic distribution of the studies was predominantly in North America and Europe (11 studies in the USA, 4 in Europe). There were a total of 456850 participants-the reported mean age of participants was 24-81 years (weighted mean $42 \pm 13$ years), the proportion of male participants ranged from $32 \%$ to $100 \%$ (weighted mean $49 \pm 9 \%$ ), and the majority of participants were Caucasian 39-100\% (weighted mean $64 \pm 6 \%$ ). Over an average follow-up time of 4-29 years, there were 11467 incident HF cases, giving an average cumulative incident HF rate of $0.97 \pm 0.11 \%$ (table 1 ).

The detailed baseline prevalence of cardiovascular and non-cardiovascular comorbidities is summarised in online supplementary appendices A1 and A2. The BMI was $25-28 \mathrm{~kg} / \mathrm{m}^{2}$ (weighted mean $26 \pm 3 \mathrm{~kg} / \mathrm{m}^{2}$ ). The prevalence of DM varied from $2 \%$ to $25 \%$ (weighted mean $4 \pm 1 \%$ ), CAD varied from $0.3 \%$ to $44 \%$ (weighted mean $2.2 \pm 0.2 \%$ ), HTN $3-58 \%$ (weighted mean $16 \pm 2 \%$ ) and left ventricular hypertrophy (LVH) $1.5-31 \%$ (weighted mean $6 \pm 1 \%$ ). In the study populations, 22$78 \%$ were either current or past smokers.

\section{Clinical factors associated with incident HF}

Twenty-seven variables were reported to be associated with incident $\mathrm{HF}$, including 20 clinical variables, 6 biomarkers and 1 echocardiographic marker. These variables were age, male gender, black race, family history of cardiac disease, excessive use of alcohol, smoking, physically inactive, obesity, education level, DM, CAD, LVH by ECG, HTN, chronic obstructive pulmonary disease, valvular heart disease (VHD), chronic kidney disease, stroke, resting heart rate, atrial fibrillation (AF), abnormal ECG which includes bundle branch block, ST-T and QRS changes, and echocardiographic left ventricular ejection fraction (EF). Biomarkers were fasting glucose, C reactive protein, creatinine, albumin, dyslipidaemia and N-terminal-pro-brain natriuretic peptide (NTproBNP).

Crude and adjusted risk ratios were extracted. The reporting details of each risk variable and overall reporting frequency are summarised in appendix B. We selected variables only if they were reported in four or more of the included studies for quantitative synthesis. Thirteen variables met this requirement. We excluded abnormal ECG due to heterogeneous criteria based on the presence of QRS changes, ${ }^{27}$ ST-T changes ${ }^{16}$ and bundle branch block. ${ }^{25}$ We also excluded dyslipidaemia and fasting glucose, due to inconsistency in categorical $^{15} 303438$ as well as continuous cut-offs of these two biomarkers ${ }^{25-27} 33$ in risk calculation between studies. Therefore, a total of 11 risk variables (age, male gender, black race, obesity, smoking, DM, CAD, HTN, LVH, VHD and AF) were selected for further synthesis. Pooled unadjusted and adjusted HRs with 95\% CIs are listed in table 2.

The details of other factors used in multivariate models of included studies are summarised in appendix C.

\section{Strength of independent association with incident HF}

Further subset meta-analyses were conducted from six studies, ${ }^{15} 1625333638$ where each of seven risk variables was mutually adjusted in models within each study. The strength of independent association for incident $\mathrm{HF}$ was highest for CAD (2.94 (1.36 to 6.33)) followed by DM (2.00 (1.68 to 2.38$)$ ) and age (per 10 years increase; 1.8 (1.13 to 2.87$)$; table 3$)$.

\section{Publication bias, sensitivity and study quality}

Egger's test for pooled adjusted risk indicated significant bias for the estimates of $\mathrm{BMI}$, male gender and $\mathrm{AF}$ (table 2B), and BMI for mutually adjusted risk estimates (table 3). No publication bias was detected for crude estimates (table 2A). Duval and Tweedie's trim and fill results are presented for all risk estimates where at least three studies were pooled. The $\operatorname{NOS}^{22}$ for cohort studies is summarised in appendix D; most studies were of high quality.

\section{Exploration of study heterogeneity}

Metaregression was performed for each of the seven risk factors in the mutually adjusted models; the following study factors were examined: follow-up time, cumulative incidence, mean age, male proportion, smoking 


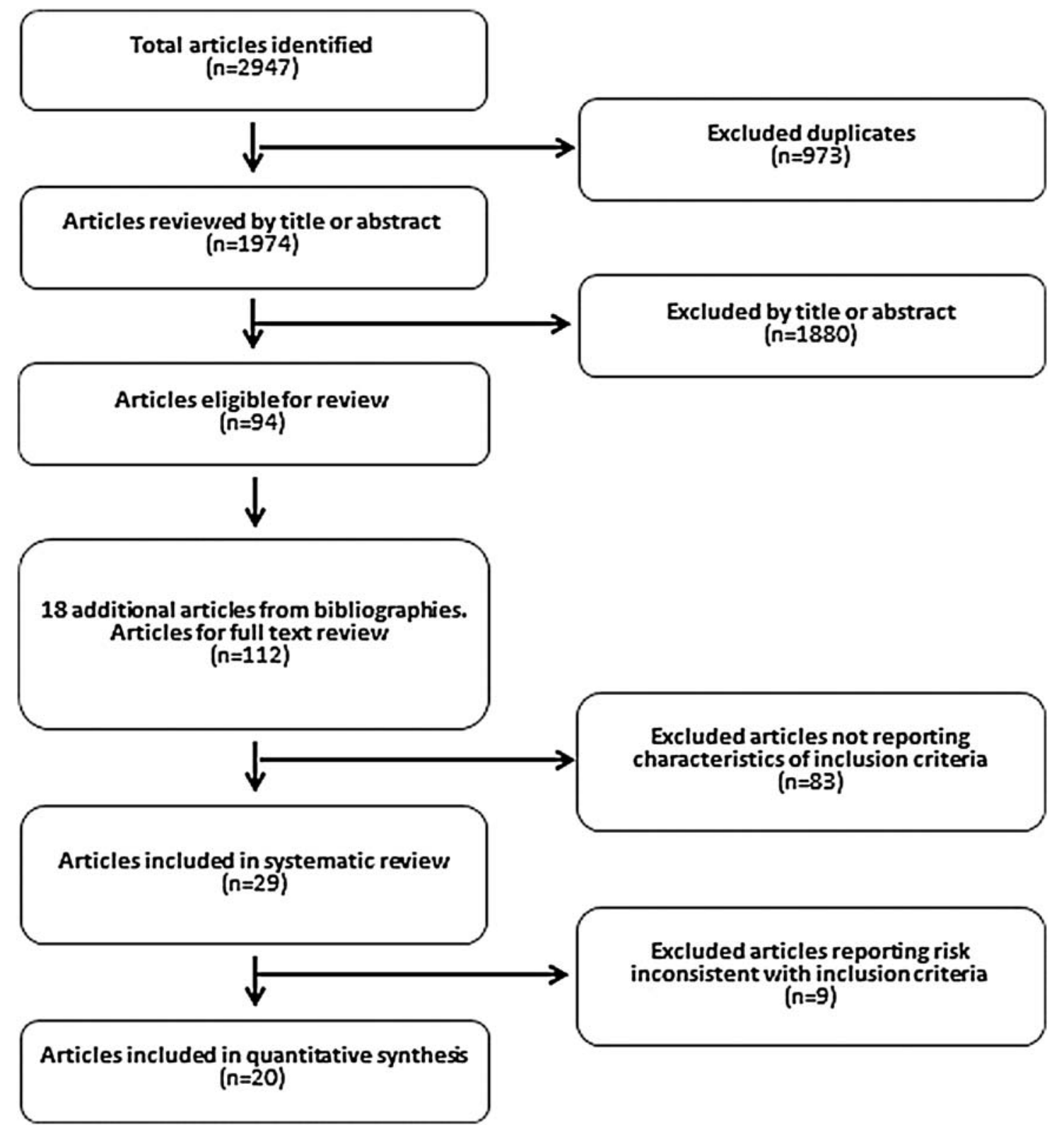

Figure 1 Process of article selection based on PRISMA.

proportion, mean BMI, DM proportion, HTN proportion, VHD proportion, CAD proportion and study quality. Even though the estimates from these seven studies were adjusted for smoking, the pooled risk effect of DM increases by approximately $10 \%$ for each $10 \%$ increase in the proportion of smokers in a study, implying some interaction between these risks. Likewise, the pooled risk effect of male sex increases by $38 \%$ for each $10 \%$ increase in the proportion of participants with diabetes in a study.

\section{DISCUSSION}

The findings of this systematic review demonstrated 11 common cardiovascular and non-cardiovascular risks associated with incident HF. Results from meta-analysis revealed the independent risk associated with the seven most common comorbidities. Knowledge of the relative effect sizes may facilitate the process of risk assessment in a community-based population. The factors most strongly independently associated with incident HF were CAD (2.94 (1.36 to 6.33)) followed by DM (2.00 (1.68 to 2.38)).

\section{Calculation of HF risk}

Although the role of HF risk factors has been documented in numerous previous publications, the reported level of risk has been heterogeneous, so the relative contribution of each factor to the development of $\mathrm{HF}$ remains controversial. To date, three population-based studies have sought to integrate risk factors into a single estimate of HF risk. ${ }^{24} 2627$ Of these, the Atherosclerosis Risk in Communities (ARIC) HF risk score is a wellvalidated parsimonious score, whereas concern has been 


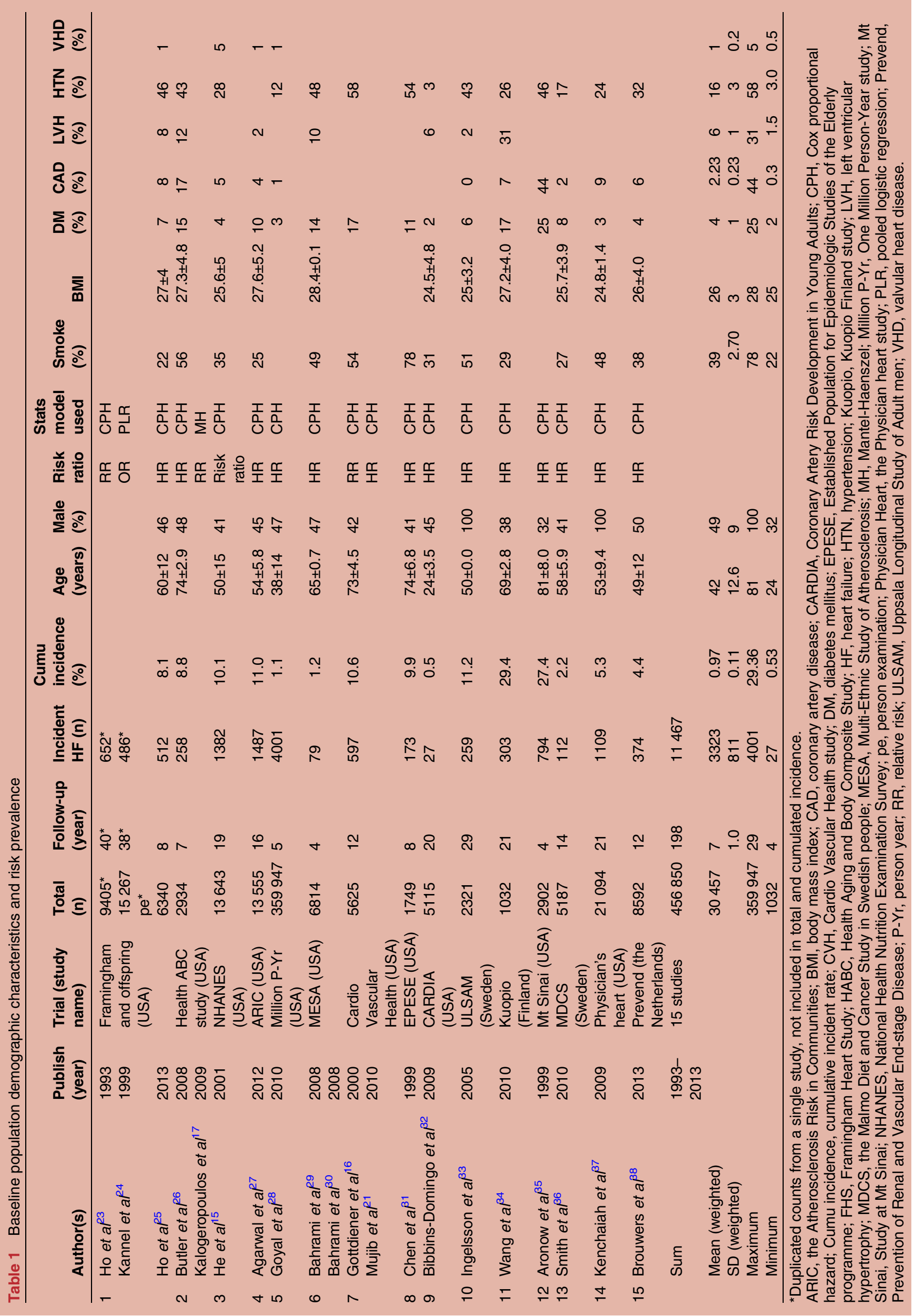


Table 2 Pooled risk estimates for common risk variables, unadjusted and adjusted for various confounders

\begin{tabular}{|c|c|c|c|c|c|c|c|c|}
\hline & Pooled HR & $95 \% \mathrm{Cl}$ & $1^{2}$ & Study (n) & $Q-\chi^{2}$ & Q-p value & Egger's test & Trim-fill HR $(95 \% \mathrm{Cl})$ \\
\hline \multicolumn{9}{|l|}{ (A) Unadjusted } \\
\hline BMI $\left(5 \mathrm{~kg} / \mathrm{m}^{2}\right)$ & 1.54 & 1.21 to 1.95 & 96.5 & 4 & 86.2 & $<0.001$ & 0.553 & $1.28(1.03$ to 1.59$)$ \\
\hline Gender (male) & 1.51 & 1.07 to 2.12 & 52.5 & 3 & 4.2 & 0.122 & 0.916 & 1.51 (1.07 to 2.12$)$ \\
\hline Smoker (yes) & 1.82 & 1.49 to 2.23 & 48.0 & 4 & 5.8 & 0.123 & 0.505 & 2.03 (1.65 to 2.49$)$ \\
\hline Race (black) & 1.78 & 1.60 to 1.98 & & 1 & & & & \\
\hline Age (10 years) & 2.29 & 2.09 to 2.51 & 57.2 & 4 & 7.0 & 0.072 & 0.842 & 2.29 (2.09 to 2.51$)$ \\
\hline HTN (yes) & 3.49 & 1.25 to 9.74 & 98.5 & 4 & 195.9 & $<0.001$ & 0.111 & 8.35 (3.16 to 22.09 ) \\
\hline Diabetes (yes) & 3.27 & 2.27 to 4.72 & 93.3 & 6 & 74.6 & $<0.001$ & 0.278 & 4.49 (3.15 to 6.39$)$ \\
\hline VHD (yes) & 3.92 & 1.85 to 8.31 & 96.2 & 2 & 26.2 & $<0.001$ & * & \\
\hline CAD (yes) & 5.07 & 2.47 to 10.40 & 97.5 & 4 & 120.5 & $<0.001$ & 0.496 & 9.63 (4.64 to 20.00 ) \\
\hline LVH (yes) & 4.4 & 2.25 to 8.58 & 87.2 & 5 & 31.3 & $<0.001$ & 0.527 & 3.29 (1.63 to 6.64$)$ \\
\hline AF (yes) & 13.77 & 11.79 to 16.08 & & 1 & & & & \\
\hline \multicolumn{9}{|l|}{ (B) Adjusted } \\
\hline BMI $\left(5 \mathrm{~kg} / \mathrm{m}^{2}\right)$ & 1.21 & 1.10 to 1.33 & 94.1 & 9 & 134.8 & $<0.001$ & 0.062 & 1.05 (0.96 to 1.16$)$ \\
\hline Gender (male) & 1.51 & 1.32 to 1.72 & 58.1 & 8 & 16.7 & 0.019 & 0.020 & 1.32 (1.14 to 1.53$)$ \\
\hline Smoker (yes) & 1.65 & 1.45 to 1.88 & 43.3 & 8 & 12.3 & 0.090 & 0.201 & 1.56 (1.34 to 1.82$)$ \\
\hline Race (black) & 0.96 & 0.75 to 1.23 & 73.3 & 4 & 11.3 & 0.010 & 0.825 & 0.91 (0.72 to 1.16$)$ \\
\hline Age (10 years) & 1.70 & 1.33 to 2.16 & 99.1 & 9 & 848.2 & $<0.001$ & 0.949 & 1.70 (1.33 to 2.16$)$ \\
\hline HTN (yes) & 1.79 & 1.41 to 2.27 & 91.9 & 11 & 123.7 & $<0.001$ & 0.533 & 2.55 (1.92 to 3.37$)$ \\
\hline Diabetes (yes) & 1.94 & 1.71 to 2.19 & 56.4 & 11 & 23.0 & 0.011 & 0.400 & 1.94 (1.71 to 2.19$)$ \\
\hline VHD (yes) & 1.74 & 1.07 to 2.84 & 92.9 & 3 & 28.0 & $<0.001$ & 0.150 & 1.74 (1.07 to 2.84$)$ \\
\hline CAD (yes) & 2.90 & 1.85 to 4.54 & 97.2 & 9 & 285.5 & $<0.001$ & 0.987 & 2.90 (1.85 to 4.54$)$ \\
\hline LVH (yes) & 2.46 & 1.71 to 3.53 & 74.1 & 6 & 19.3 & 0.002 & 0.431 & $2.17(1.47$ to 3.19$)$ \\
\hline AF (yes) & 1.88 & 1.60 to 2.21 & 16.2 & 4 & 3.6 & 0.310 & 0.020 & 1.99 (1.66 to 2.39$)$ \\
\hline
\end{tabular}

*Egger's test was used only if the number of studies was three or greater.

AF, atrial fibrillation; BMI, body mass index; CAD, coronary artery disease; HTN, hypertension; LVH, left ventricular hypertrophy; VHD, valvular heart disease.

Columns in bold correspond to pooled HR $(95 \% \mathrm{Cl})$ to differentiate from the Trim-fill $\mathrm{HR}(95 \% \mathrm{Cl})$ in the same table. The latter is obtained from Duval and Tweedie's method to check for publication bias.

expressed regarding the selection of patients into the Framingham Heart Failure Risk Score (which is much influenced by ischaemic aetiology), and the Health ABC Heart Failure Score requires blood testing that may not be accessible at community screening.

It is paradoxical that while the performance of an echocardiogram is considered appropriate in patients with symptomatic HF, its use in the preclinical stage is considered inappropriate. ${ }^{39}$ Perhaps this is the reason that screening for HF has not been widely applied, even in at-risk patients such as those with DM, HTN and $\mathrm{CAD}$, despite the wide availability of echocardiographic assessment of systolic and diastolic dysfunction. Moreover, left ventricular (LV) assessment using twodimensional imaging may be hard to reproduce, and although there have been initial reports of both in community studies, ${ }^{40}$ the place of both in community screening is undefined. In any case, some clinical definition of risk would still be required.

\section{HF screening}

SBHF lies between overt HF (stages $\mathrm{C}$ and D) and patients with HF risk factors (stage A). These asymptomatic patients have evidence of LV damage, which may be

Table 3 Pooled HR estimates for mutually adjusted risk variables

\begin{tabular}{|c|c|c|c|c|c|c|c|c|}
\hline & Pooled HR & $95 \% \mathrm{Cl}$ & $I^{2}$ & Study $(n)^{*}$ & $Q-\chi^{2}$ & Q-p value & Egger's test & Trim-fill HR $(95 \% \mathrm{Cl})$ \\
\hline BMI $\left(5 \mathrm{~kg} / \mathrm{m}^{2}\right)$ & 1.15 & 1.06 to 1.25 & 89.8 & 5 & 39.34 & $<0.001$ & 0.039 & 1.06 (0.96 to 1.16$)$ \\
\hline Gender (male) & 1.52 & 1.24 to 1.87 & 71.5 & 5 & 14.05 & 0.007 & 0.107 & 1.27 (1.03 to 1.56$)$ \\
\hline Smoker (yes) & 1.60 & 1.45 to 1.77 & 0.0 & 5 & 2.69 & 0.611 & 0.783 & $1.60(1.45$ to 1.77$)$ \\
\hline HTN (yes) & 1.61 & 1.33 to 1.96 & 64.1 & 5 & 11.14 & 0.025 & 0.358 & $1.41(1.15$ to 1.73$)$ \\
\hline Age (10 years) & 1.80 & 1.13 to 2.87 & 99.1 & 4 & 331.4 & $<0.001$ & 0.64 & 2.41 (1.49 to 3.91$)$ \\
\hline DM (yes) & 2.00 & 1.68 to 2.38 & 50.6 & 6 & 10.12 & 0.072 & 0.841 & 2.00 (1.68 to 2.38$)$ \\
\hline CAD (yes) & 2.94 & 1.36 to 6.33 & 97.7 & 6 & 212.6 & $<0.001$ & 0.583 & 6.71 (2.69 to 16.74$)$ \\
\hline
\end{tabular}

${ }^{*}$ Number of studies included in estimates for each listed risk factor.

BMI, body mass index; CAD, coronary artery disease; DM, diabetes mellitus; HTN, hypertension.

Columns in bold correspond to pooled $\mathrm{HR}(95 \% \mathrm{Cl})$ to differentiate from the Trim-fill HR $(95 \% \mathrm{Cl})$ in the same table. The latter is obtained from Duval and Tweedie's method to check for publication bias. 
detected as disturbances of LV structure or function, which predispose towards the development of $\mathrm{HF}^{41}$ SBHF is relatively easy to identify in patients with previous myocardial infarction and regional dysfunction, or with reduced ejection fraction. However, nearly $50 \%$ of $\mathrm{HF}$ is of non-ischaemic origin, ${ }^{10}$ and in this circumstance, the identification of SBHF may be difficult in the absence of LVH.

Although HF may be prevented by control of HF risk factors, early detection of LV dysfunction may permit the institution of measures that prevent progression of the problem. ${ }^{4}{ }^{42}{ }^{43}$ Screening for SBHF is supported by previous studies of subclinical LV systolic and diastolic dysfunction. The prevalence of asymptomatic EF $<50 \%$ is $7.2 \%$ in those aged $60-69$ years and doubles to $14.3 \%$ in those aged $>80$ years. ${ }^{44}$ The prevalence of diastolic dysfunction varies with grade among patients with different risk groups. In older ( $>65$ years) patients with a diagnosis of HTN or coronary disease, the prevalence of mild diastolic dysfunction is $36 \%$, whereas that of moderate or severe diastolic dysfunction is $16 \%{ }^{45}$ Abnormal myocardial function can be documented in $20-30 \%$ of patients with obesity and diabetes. ${ }^{46} 47$

The application of any screening test is most effective when the condition is of at least moderate prevalence in the population under study. For example, focusing the screening effort on those with non-ischaemic risk factors for HF (diabetes, HTN, overweight, MS, cardiotoxic chemotherapy, familial cardiomyopathy) would permit restriction of screening tests to the group most likely to have a problem. Nonetheless, these HF risks are highly prevalent in the general population and their relative and additive importance is not well known.

The consistency of association of various risk factors with HF supports the concept that HF is predictable in many patients. The development of this simple risk calculation strategy derived from this study could be used to focus resources (eg, open access echocardiography) on at-risk patients without ischaemia. However, the predictive value of the risk calculation, the benefit of imaging surveillance and the cost-effectiveness of screening of stage A HF in the community will need to be validated prospectively. We are undertaking this at present in a population-based study (http://www.anzctr.org.au/; ACTRN12614000080628).

\section{Limitations}

Like all meta-analyses, this work is limited by variations in the original studies, although all involved at-risk individuals. Likewise, the constituent observational studies may be limited by biases in the recruitment process. The high levels of $\mathrm{I}^{2}$ attest to substantial heterogeneity between studies. The original intention of the analysis was to develop a risk score using the available clinical variables. This was limited by the heterogeneity in the studies, particularly in the various cohorts used in each study and in the variables used for adjustment. Without access to individual-level data, we can only propose that the combined risk measures derived from this study be used as a marker of the magnitude rather than as exact risk estimates. Furthermore, our primary interest was to identify and quantify the potential HF risks in non-ischaemic HF. While CAD is ubiquitous in these, the proportion with $\mathrm{CAD}$ is low (weighted average 2.2\%, table 1 ). Moreover, the benefit of a meta-regression is that we were able to address the role of other factors independent of CAD. Finally, this systematic review was not registered prospectively.

\section{CONCLUSION}

This systematic review and meta-analysis of 456850 participants shows that CAD, diabetes, age, HTN, smoking, male gender and increased BMI are consistently and independently associated with a higher risk of incident HF. AF, LVH and valve heart disease are also strongly associated with incident HF. The estimation of HF risk may become useful in selection of asymptomatic patients for imaging as sensitive, new imaging and biochemical techniques for identification of LV dysfunction become more widely available.

Contributors HY was involved in reviewing, synthesis, analysis and drafting. $\mathrm{KN}$ was involved in reviewing and drafting. PO was involved in analysis and drafting. THM was involved in design, synthesis, analysis and drafting.

Funding HY is supported by a Health Professional Scholarship from the National Heart Foundation of Australia (100307).

\section{Competing interests None.}

Provenance and peer review Not commissioned; externally peer reviewed.

Data sharing statement No additional data are available.

Open Access This is an Open Access article distributed in accordance with the Creative Commons Attribution Non Commercial (CC BY-NC 4.0) license, which permits others to distribute, remix, adapt, build upon this work noncommercially, and license their derivative works on different terms, provided the original work is properly cited and the use is non-commercial. See: http:// creativecommons.org/licenses/by-nc/4.0/

\section{REFERENCE}

1. McMurray JJ, Petrie MC, Murdoch DR, et al. Clinical epidemiology of heart failure: public and private health burden. Eur Heart J 1998;19 (Suppl P):P9-16.

2. Hunt SA, Abraham WT, Chin MH, et al. 2009 Focused update incorporated into the ACC/AHA 2005 guidelines for the diagnosis and management of heart failure in adults. J Am Coll Cardiol 2009;53:e1-90.

3. Lloyd-Jones D, Adams R, Carnethon M, et al. Heart disease and stroke statistics-2009 update: a report from the American Heart Association Statistics Committee and Stroke Statistics Subcommittee. Circulation 2009;119:e21-181.

4. SOLVD Investigators. Effect of enalapril on survival in patients with reduced left ventricular ejection fractions and congestive heart failure. The SOLVD Investigators. N Engl J Med 1991;325:293-302.

5. SOLVD Investigators. Effect of enalapril on mortality and the development of heart failure in asymptomatic patients with reduced left ventricular ejection fractions. The SOLVD Investigattors. $N$ Engl $J$ Med 1992;327:685-91.

6. Genovesi Ebert A, Colivicchi F, Malvezzi Caracciolo M, et al. Additive beneficial effects of beta blockers in the prevention of symptomatic heart failure. Monaldi Arch Chest Dis 2009;72:18-22.

7. Yusuf $\mathrm{S}$, Sleight $\mathrm{P}$, Pogue J, et al. Effects of an angiotensinconverting-enzyme inhibitor, ramipril, on cardiovascular events in high-risk patients. The Heart Outcomes Prevention Evaluation Study Investigators. N Engl J Med 2000;342:145-53. 
8. Pfeffer MA, Braunwald E, Moye LA, et al. Effect of captopril on mortality and morbidity in patients with left ventricular dysfunction after myocardial infarction. Results of the survival and ventricular enlargement trial. The SAVE Investigators. N Engl J Med 1992;327:669-77.

9. Vantrimpont $\mathrm{P}$, Rouleau JL, Wun CC, et al. Additive beneficial effects of beta-blockers to angiotensin-converting enzyme inhibitors in the Survival and Ventricular Enlargement (SAVE) Study. SAVE Investigators. J Am Coll Cardiol 1997;29:229-36.

10. Ammar KA, Jacobsen SJ, Mahoney DW, et al. Prevalence and prognostic significance of heart failure stages: application of the American College of Cardiology/American Heart Association Heart Failure Staging Criteria in the Community. Circulation 2007;115:1563-70.

11. Kenchaiah S, Narula J, Vasan RS. Risk factors for heart failure. Med Clin North Am 2004:88:1145-72.

12. Butler J. Primary prevention of heart failure. ISRN Cardiol 2012;2012:982417.

13. Liberati A, Altman DG, Tetzlaff $\mathrm{J}$, et al. The PRISMA statement for reporting systematic reviews and meta-analyses of studies that evaluate healthcare interventions: explanation and elaboration. $B M J$ 2009;339:b2700

14. Shi JQ, Copas JB. Meta-analysis for trend estimation. Stat Med 2004;23:3-19; discussion 159-62.

15. He J, Ogden LG, Bazzano LA, et al. Risk factors for congestive heart failure in US men and women: NHANES I epidemiologic follow-up study. Arch Intern Med 2001;161:996-1002.

16. Gottdiener JS, Arnold AM, Aurigemma GP, et al. Predictors of congestive heart failure in the elderly: the Cardiovascular Health Study. J Am Coll Cardiol 2000;35:1628-37.

17. Kalogeropoulos A, Georgiopoulou V, Kritchevsky SB, et al. Epidemiology of incident heart failure in a contemporary elderly cohort: the health, aging, and body composition study. Arch Intern Med 2009;169:708-15.

18. Eriksson $\mathrm{H}$, Svardsudd K, Larsson B, et al. Risk factors for heart failure in the general population: the study of men born in 1913. Eur Heart J 1989;10:647-56.

19. Wilhelmsen $\mathrm{L}$, Rosengren $\mathrm{A}$, Eriksson $\mathrm{H}$, et al. Heart failure in the general population of men-morbidity, risk factors and prognosis. J Intern Med 2001;249:253-61.

20. DerSimonian R, Laird N. Meta-analysis in clinical trials. Control Clin Trials 1986;7:177-88

21. Mujib M, Desai R, Levitan EB, et al. Prospective population studies of incident heart failure without data on baseline left ventricular ejection fraction. Arch Med Sci 2010;6:686-8.

22. Wells GA, Shea B, O'Connell D, et al. The Newcastle-Ottawa Scale (NOS) for assessing the quality if nonrandomized studies in meta-analyses. http://wwwohrica/programs/clinical_epidemiology/ oxfordasp

23. Ho KK, Pinsky JL, Kannel WB, et al. The epidemiology of heart failure: the Framingham Study. J Am Coll Cardiol 1993;22(4 Suppl A): $6 \mathrm{~A}-13 \mathrm{~A}$

24. Kannel WB, D'Agostino RB, Silbershatz $\mathrm{H}$, et al. Profile for estimating risk of heart failure. Arch Intern Med 1999;159:1197-204.

25. Ho JE, Lyass A, Lee DS, et al. Predictors of new-onset heart failure: differences in preserved versus reduced ejection fraction. Circ Heart Fail 2013;6:279-86

26. Butler J, Kalogeropoulos A, Georgiopoulou V, et al. Incident heart failure prediction in the elderly: the health $\mathrm{ABC}$ heart failure score. Circ Heart Fail 2008;1:125-33.

27. Agarwal SK, Chambless LE, Ballantyne CM, et al. Prediction of incident heart failure in general practice: the Atherosclerosis Risk in Communities (ARIC) Study. Circ Heart Fail 2012;5:422-9.

28. Goyal A, Norton CR, Thomas TN, et al. Predictors of incident heart failure in a large insured population: a one million person-year follow-up study. Circ Heart Fail 2010;3:698-705.

29. Bahrami H, Bluemke DA, Kronmal R, et al. Novel metabolic risk factors for incident heart failure and their relationship with obesity: the MESA (Multi-Ethnic Study of Atherosclerosis) study. J Am Coll Cardiol 2008;51:1775-83.
30. Bahrami H, Kronmal R, Bluemke DA, et al. Differences in the incidence of congestive heart failure by ethnicity: the multi-ethnic study of atherosclerosis. Arch Intern Med 2008:168:2138-45.

31. Chen YT, Vaccarino V, Williams CS, et al. Risk factors for heart failure in the elderly: a prospective community-based study. $A m \mathrm{~J}$ Med 1999;106:605-12.

32. Bibbins-Domingo K, Pletcher MJ, Lin F, et al. Racial differences in incident heart failure among young adults. $N$ Engl $J$ Med 2009;360:1179-90.

33. Ingelsson E, Arnlov J, Sundstrom J, et al. Novel metabolic risk factors for heart failure. J Am Coll Cardiol 2005;46:2054-60.

34. Wang J, Sarnola K, Ruotsalainen S, et al. The metabolic syndrome predicts incident congestive heart failure: A 20-year follow-up study of elderly Finns. Atherosclerosis 2010;210:237-42.

35. Aronow WS, Ahn C, Kronzon I. Comparison of incidences of congestive heart failure in older African-Americans, Hispanics, and whites. Am J Cardiol 1999;84:611-12, A9.

36. Smith JG, Newton-Cheh C, Almgren P, et al. Assessment of conventional cardiovascular risk factors and multiple biomarkers for the prediction of incident heart failure and atrial fibrillation. J Am Coll Cardiol 2010;56:1712-19.

37. Kenchaiah S, Sesso HD, Gaziano JM. Body mass index and vigorous physical activity and the risk of heart failure among men. Circulation 2009;119:44-52.

38. Brouwers FP, de Boer RA, van der Harst $P$, et al. Incidence and epidemiology of new onset heart failure with preserved vs. reduced ejection fraction in a community-based cohort: 11-year follow-up of PREVEND. Eur Heart J 2013;34:1424-31.

39. Douglas PS, Garcia MJ, Haines DE, et al. ACCF/ASE/AHA/ASNC/ HFSA/HRS/SCAI/SCCM/SCCT/SCMR 2011 appropriate use criteria for echocardiography. A report of the American College of Cardiology Foundation Appropriate Use Criteria Task Force, American Society of Echocardiography, American Heart Association, American Society of Nuclear Cardiology, Heart Failure Society of America, Heart Rhythm Society, Society for Cardiovascular Angiography and Interventions, Society of Critical Care Medicine, Society of Cardiovascular Computed Tomography, Society for Cardiovascular Magnetic Resonance American College of Chest Physicians. J Am Soc Echocardiogr 2011;24:229-67.

40. Thorstensen A, Dalen $\mathrm{H}$, Amundsen $\mathrm{BH}$, et al. Reproducibility in echocardiographic assessment of the left ventricular global and regional function, the HUNT study. Eur J Echocardiogr 2010;11:149-56.

41. Jessup M, Abraham WT, Casey DE, et al. 2009 Focused update: ACCF/AHA guidelines for the diagnosis and management of heart failure in adults: a report of the American College of Cardiology Foundation/American Heart Association Task Force on Practice Guidelines: developed in collaboration with the International Society for Heart and Lung Transplantation. Circulation 2009;119:1977-2016.

42. Carrington MJ, Stewart S. Bridging the gap in heart failure prevention rationale and design of the Nurse-led Intervention for Less Chronic Heart Failure (NIL-CHF) Study. Eur J Heart Fail 2010;12:82-8.

43. Colucci WS. Landmark study: the Carvedilol Post-Infarct Survival Control in Left Ventricular Dysfunction Study (CAPRICORN). Am J Cardiol 2004;93:(9A):13B-6B.

44. Wang TJ, Evans JC, Benjamin EJ, et al. Natural history of asymptomatic left ventricular systolic dysfunction in the community. Circulation 2003;108:977-82.

45. Bursi F, Weston SA, Redfield MM, et al. Systolic and diastolic heart failure in the community. JAMA 2006;296:2209-16.

46. Ernande L, Rietzschel ER, Bergerot C, et al. Impaired myocardial radial function in asymptomatic patients with type 2 diabetes mellitus: a Speckle-Tracking Imaging Study. J Am Soc Echocardiogr 2010;23:1266-72.

47. Ernande L, Bergerot C, Rietzschel ER, et al. Diastolic dysfunction in patients with type 2 diabetes mellitus: is it really the first marker of diabetic cardiomyopathy? J Am Soc Echocardiogr 2011; 24:1268-75.e1. 